\title{
Effect of Varying Initial Processing Temperature on Mechanical Properties of Carbon Epoxy Composites
}

\author{
Wajid Ali Khan'a ${ }^{1 a}$ Jawad Khalid², Arsalan Raja ${ }^{1 b}$ \\ RECEIVED ON 22.12.2019, ACCEPTED ON 16.12.2020
}

\begin{abstract}
Use of composite materials for structural application has greatly flourished in last three decades. Mechanical properties of carbon composite are largely dependent on the processing parameters like processing temperature, compaction pressure, resin flow and fiber orientation. Processing temperature has an important and decisive role in defining the properties of the composites and absence of proper temperature can cause reduced mechanical properties and defects like wrinkles and voids. This study focuses on varying the initial processing temperature for carbon laminates and documents the effect on mechanical properties of the composite produced. The testing range of temperature was specified by the choice of resin. It was found that the mechanical properties like tensile, bending and shear strength increased non-linearly with increasing initial temperature of processing. Increase of fiber volume fraction, fiber weight fraction and density were observed which along with better resin distribution, resin flow and increased laminate compaction can be attributed as key reasons of increased mechanical properties.
\end{abstract}

Keywords: Process Parameters, Temperature, Mechanical properties, Carbon Composite, Fiber Fraction.

\section{INTRODUCTION}

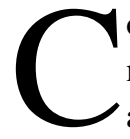
omposite products have become popular in many industries including aerospace industry and one of the reasons is that these composites can be tailored and customized to have specific properties in required directions. This customization has allowed to produce composite laminates having complex near net shapes thus helping in reducing the manufacturing cost. Carbon fibers-based laminates have by far the best specific mechanical properties and are used widely with a variety of matrix materials thus resulting in a range of processing parameters. The commercial aviation industry has exploited the benefits of fuel economy, reduced maintenance and running costs by using composite materials in production of the aircrafts. Carbon and its hybrid composites have the leading share in current aerospace industry due to attractive properties of parts like corrosion resistance, better fatigue life and reduced machining requirements than traditional metallic and non-metallic materials.

Once a design of any structural component based on composite laminates is finalized for performance parameters, the focus shifts towards the control of process parameters as the properties of any such laminate are also influenced by the processing method and conditions. Key parameters of concern are fiber orientation, resin flow and distribution, curing temperature and pressure, compaction along with timing and sequence of different processes, which dictate the final integrity of structural composite laminate produced [1-3]. It was reported that an increase in processing temperature resulted in elevated mechanical properties and absence of defects [4]. It also provides quick processing which saves cost and time that is an added benefit as well. It was noted that

${ }^{1}$ Department of Mechanical Engineering, University of Hafr Al Batin, 31991, Kingdom of Saudi Arabia.

Email: awajidkhan@uhb.edu.sa (Corresponding Author), barsalanr@uhb.edu.sa

${ }^{2}$ National University of Science and Technology, Islamabad, Pakistan. Email: jawad_khalid@hotmail.com

This is an open access article published by Mehran University of Engineering and Technology, Jamshoro under CC BY 4.0 International License. 
in order to completely determine the behavior of a composite part during its life cycle, the entire set of manufacturing process variables (resin, mold and environmental temperature, pressure and gel time) have to be clearly known and included in the design of experiment while quantifying the effects of these parameters [4]. Rapid curing epoxy resin system and preheated the mold for shortening the cycle time in order to adopt to the demands of higher production rates have been studied [5-7]. In another investigation the effect of curing temperature on flexural properties of silica based geo-polymer carbon reinforced composite were determined and experimentally verified the optimum curing temperature for flexural strength [11]. Alkan et al. [13] focused on the effects of temperature on glass fiber composites in structural applications. The temperature effects during the time of processing or their exposure alter the mechanical properties of composites in general and particularly in case of polymer matrix composites.

Lu et al. [5] studied four different parameters including melting temperature, molding pressure, crystallization temperature and resin content to investigate their effect on tensile and bending strength of continuous carbon fiber and Polyether Ether Ketone (PEEK) composites. The results showed significant variation of properties due to varying pressure and resin content, but effect of temperature was not fully investigated. Van-Pham et al. studied ABS reinforced banana fibers using X-ray CT imaging for the relationship between mechanical properties and structure of the processed composite with variation in parameters such as processing time, temperature and pressure on tensile and flexural properties. It was observed that these properties were inversely proportional to porosity and higher pressures resulted in cracks. An optimal temperature and pressure were recommended for this composite by the authors [10].

Zhang et al. [7] focused on wool fiber composites processed by compression molding and optimum processing parameters were identified for the combination. Choupin tested wet impregnation processing parameters for mechanical properties with phenolic resin for the mechanical properties [9] as was done in another research by Michlowski [8]. PEEK thermoplastic composites and their processing parameters were linked in another study and Schell et al. [14] described the significance of equipment, production rate and energy cost for processing at lowest possible pressure and temperature with shortest cycle time.

Although all these parameters have significant effect on the properties of laminates, this study focuses on effect varying temperature during different processing stages as it is thought that it plays a pivotal role in product performance properties. Absence of proper processing temperature causes defects like voids, wrinkles and decrease in mechanical properties vital to service life of the part. It is noted that many recent studies have tried to correlate the initial processing parameters to the different mechanical properties. However, this study focused on mechanical properties at different initial temperature of processing for carbon composite.

\section{METHODOLOGY}

\subsection{Correlation of Composite Properties with Temperature}

T300 carbon fiber plain weaved cloth and Araldite 5052 are chosen as the constituent materials for testing incrementally between $20^{\circ} \mathrm{C}$ to $80^{\circ} \mathrm{C}$ since it is one of the most common and popular combination of materials in aerospace industry. Processing at a higher temperature results in better profiles [10-12]. However, there are some limitations to that as having too high a temperature may cause the laminate to overcook from the outside, leaving the matrix undercooked at the inner sections thus weakening the profiles. There are no significant results available for most of the commonly used fiber/ matrix combinations to quantify the benefits of increasing the processing temperatures. This study is aimed at partially filling this knowledge gap and focuses on one fiber/matrix materials combination. The processing temperature was raised in small increments to be able to observe any significant change in the properties. The final point was where any further increment in the processing temperature meant reaching the gel temperature and not allowing enough time for resin to spread uniformly within the profile, thus resulting in reduction of the strength of the profiles. Another key 
advantage of the higher processing temperatures is the faster processing and curing of products which has not been quantified in this research. This research can be used by manufacturing industry and other industrial purposes where performance-based application of carbon composite is required.

Mechanical properties of composites are dependent on processing parameters. Therefore, control and knowledge of process is critical in obtaining design targets of composites. If all other processing parameters are not changed along with the design parameters, the flow of the matrix material can be described by using the control law for one dimensional flow within the reinforcements. The flow of resin through the fabric is governed by Darcy's law:

$\mathrm{v}=-\frac{K_{\mathrm{z}}}{\mu} \frac{\mathrm{dP}}{\mathrm{dx}}$

(One dimensional flow through thickness)

where: $K_{z}$ is fabric permeability in the $z$ direction, $\mu$ is resin viscosity while $\frac{\mathrm{dP}}{\mathrm{dx}}$ is the pressure gradient.

The flow through various parts of the mold is described by Navier-Stokes equation which is given as follow:

$\rho \frac{\partial u_{j}}{\partial t}+\rho u_{k} \frac{\partial u_{k}}{\partial x_{k}}=-\frac{\partial P}{\partial x_{k}}+\mu \frac{\partial^{2} u_{j}}{\partial x_{i}^{2}}+\rho f_{j}$

where: $\rho$ is density, $u$ is velocity, $\mathrm{x}$ is coordinate direction, $\mu$ is resin viscosity, $\mathrm{t}$ is time, $\mathrm{P}$ is pressure while $\mathrm{f}$ is body force.

These two equations highlight the role of temperature of processing as resin viscosity, velocity and density are dependent on it. Fiber permeability and pressure drop during flow also play an influencing role with concern to resin flow and distribution $[15,16]$. Some of the mechanical properties that are influenced by matrix only, decrease with increasing temperature whereas the properties influenced by reinforcement are unaffected, however, fiber volume fraction is expected to improve. Delamination or separation of plies in a composite has been found to be encouraged by temperature rise during processing. Mechanical properties like strength, stiffness, compression and tensile strength are all influenced by the fiber. These properties are adversely affected by temperature fluctuation during processing.

\subsection{Experimental Methodology}

The material used as reinforcement is carbon fiber (T300) in $3 \mathrm{k}$ plain weave configuration. A piece of the fabric is shown in Fig. 1.

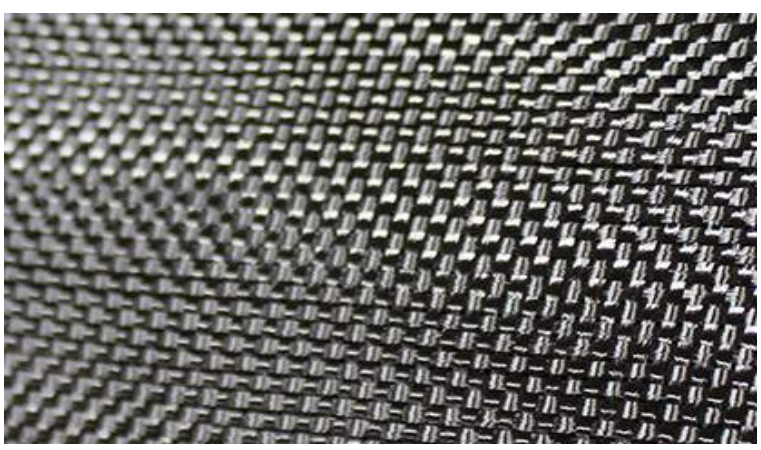

Fig 1: Sample of 3k Plain Weaved Carbon Cloth

As a general trend, desirable properties are reduced by the non-presence of proper temperature during manufacturing of composites $[17,18]$. It is due to the fact that resin volume and voids influence fiber dependent mechanical properties [19]. As temperature influences both these factors thus, a non-linear behavior is exhibited between mechanical properties and temperature.

The importance of temperature as processing parameter with significant relationship with other parameters clearly indicates its importance in structural composite production. The use of materials is customized as hinted earlier, offers significant advantage. However, it has also made the behavior different and ascertaining of properties in all scenarios of structural composite laminate vital. The experimental results verify the non-linearity of mechanical properties with change in temperature [2022].

The material selected as matrix was Araldite epoxy (5052) which is widely used in aerospace industry. Sample laminates were vacuum bagged on preheated surface $\left(20^{\circ} \mathrm{C}\right.$ to $80^{\circ} \mathrm{C}$ with $20^{\circ} \mathrm{C}$ increments) for two hours and then post cured at room temperature for 16 hours to investigate the effects on mechanical properties of carbon composite keeping the vacuum

Mehran University Research Journal of Engineering and Technology, Vol. 40, No. 4, October 2021 [p-ISSN: 0254-7821, e-ISSN: 2413-7219] 
pressure same for all tests. Test temperature range was dependent on properties of matrix and all testing was dependent on properties of matrix and all testing was done according to applicable ASTM standards. Machining of sample plates was performed with precision using modern machine tools. A schematic of vacuum bagging used is shown in Fig. 2.

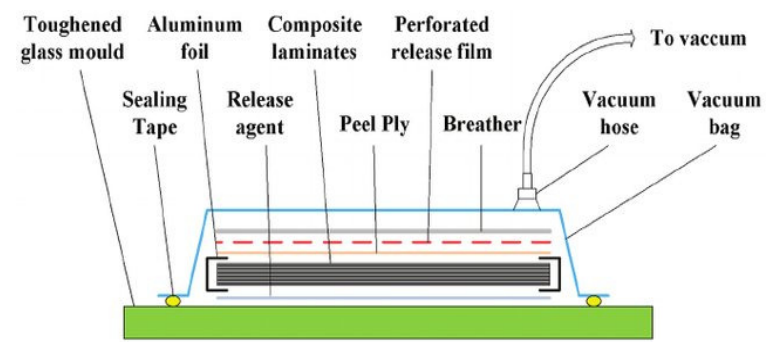

Fig 2: Schematic Vacuum Bagging Process [23]

The tensile strength is calculated by the following equation. $\sigma_{\mathrm{T}}=\frac{\mathrm{P}_{\max }}{\mathrm{bh}}$, where $\sigma_{\mathrm{T}}$ is the tensile strength $\mathrm{P}_{\max }$ is the maximum force carried by the sample before failure. $\mathrm{b}$ and $\mathrm{h}$ are the width and thickness of the test samples.

The bending or flexural strength of the test samples was calculated using the following equation $\sigma_{\mathrm{b}}=\frac{3 \mathrm{PL}}{2 \mathrm{bh}^{2}}$

$\sigma_{\mathrm{b}}$ is the bending or flexural strength, $\mathrm{P}$ is the applied force, $\mathrm{L}$ is the supported span $\mathrm{b}$ and $\mathrm{h}$ are the width and thickness of the specimen.

\subsection{Sample Specifications:}

ASTM D3039/D3039M is used for tensile testing using Electromechanical universal testing machine Sintech 10-G. The dimensions of the samples produced for testing are mentioned in Fig. 3. The

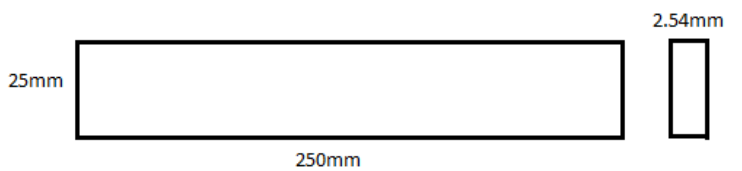

Fig 3: Test Sample for Tensile Strength

thickness of $2.54 \mathrm{~mm}$ is achieved by using the 12 layers of at $0^{\circ} / 90^{\circ}$ orientation for all the samples. The final samples are machined out from a big laminate sheet thus introducing similar residual stresses in all the sample; so it can be justifiably assumed that the only variable affecting the properties of the samples is processing temperature and holding times. Universal testing machine with mechanical clamping and a load cell of $50 \mathrm{kN}$ with crosshead speed set $5 \mathrm{~mm} / \mathrm{min}$ was used for tensile testing.

\subsection{Density Calculation}

Composite density was determined by using ASTM D792 Test for specific gravity and density of plastics by displacement on Mettler Toledo precision balance ME 103T/00. One sample was obtained from each plate used for different test. The sample weighed $5 \mathrm{~g}$ each. The immersion fluid utilized was water. Following average densities were obtained at $23^{\circ} \mathrm{C}$ testing temperature.

The weight was calculated for up to 4 significant figures using accurate and calibrated digital balance. Average values were calculated to reduce any error and are given below for all 5 sample plates per temperature test point. It should be noted that all the tests for density and strength calculations were repeated at least five times with very little variation in results $( \pm 1.8 \%)$ and average values are reported in this paper. The better density and higher volume fractions at higher processing temperature is attributed to the lower viscosity thus better ability of the resin to wet the reinforcement and squeezing out any excessive matrix content keeping other parameters same.

\begin{tabular}{|c|c|}
\hline \multicolumn{2}{|c|}{$\begin{array}{l}\text { Table 1: Density at different processing } \\
\text { temperature }\end{array}$} \\
\hline Plates temperature & $\begin{array}{c}\text { Composed Density } \\
\left(\mathrm{kg} / \mathrm{m}^{3}\right)\end{array}$ \\
\hline $20^{\circ} \mathrm{C}$ & 1354 \\
\hline $40^{\circ} \mathrm{C}$ & 1395 \\
\hline $60^{\circ} \mathrm{C}$ & 1421 \\
\hline $80^{\circ} \mathrm{C}$ & 1428 \\
\hline
\end{tabular}

\subsection{Fiber volume fraction and weight fraction Calculation}

The calculation for fiber volume fraction using experimentally acquired data for density is as follows:

Composite density $(\rho c)=V_{f} \cdot \rho_{f}+\left(1-V_{f}\right) \cdot \rho_{r}$ 
$\mathrm{V}_{\mathrm{f}}=$ volume fraction of fibers, $\rho_{\mathrm{f}}=$ density of fibers, $\rho_{\mathrm{r}}=$ density of resin,

$\rho_{f}=$ density of fibers $=1.76 \mathrm{~g} / \mathrm{cm}^{3}=1760 \mathrm{~kg} / \mathrm{m}^{3}$

$\rho_{r}=$ density of resin (mix of epoxy and hardener) Epoxy $=1.17 \mathrm{~g} / \mathrm{cm}^{3}$, Hardener $=0.95 \mathrm{~g} / \mathrm{cm}^{3}$.

Mix ratio $=100 / 38$ by weight $(72.5 \%$ epoxy, $27.5 \%$ hardener)

Density of epoxy and hardener mixture: $=$ $1.17 \times 0.725+0.95 \times 0.275=1.10 \mathrm{~g} / \mathrm{cm}^{3}=1100 \mathrm{~kg} / \mathrm{m}^{3}$

Using the data in laminate density relation to obtain fiber volume fraction and calculating fiber weight fraction in the composite.

Table 2 presents the fiber volume fractions at different processing temperatures of the specimens and as expected shows an increase in the value at higher temperatures. This is consistent with higher values of density at higher processing temperatures.

\begin{tabular}{|c|c|c|}
\hline \multicolumn{3}{|c|}{$\begin{array}{l}\text { Table 2: Fiber fractions at given processing } \\
\text { conditions }\end{array}$} \\
\hline $\begin{array}{c}\text { Temperature } \\
\text { test point }\end{array}$ & $\begin{array}{l}\text { Volume } \\
\text { fraction }\end{array}$ & $\begin{array}{l}\text { Weight } \\
\text { fraction }\end{array}$ \\
\hline $20^{\circ} \mathrm{C}$ & 0.3848 & 0.5001 \\
\hline $40^{\circ} \mathrm{C}$ & 0.4469 & 0.5638 \\
\hline $60^{\circ} \mathrm{C}$ & 0.4863 & 0.6023 \\
\hline $80^{\circ} \mathrm{C}$ & 0.4969 & 0.6129 \\
\hline
\end{tabular}

\section{RESULTS AND DISCUSSION}

\subsection{Tensile Testing}

Table 3 presents the tensile strength of different samples at mentioned initial processing temperatures. Five different samples were tested, and results are averaged to avoid any erroneous reading and to rule out the variations in tensile strength due to other processing parameters such as pressure, void content and orientation of the fibers within the laminates. It can clearly be seen from the results in the table that the tensile strength of the laminates is increasing with increasing processing temperature, while all other processing and test parameters are kept the same.

An increase of almost $35 \%$ is seen from $20^{\circ} \mathrm{C}$ to $80^{\circ} \mathrm{C}$ which is a very significant increase and can play a critical role in the design of aerospace products using the same materials. The increase is thought to be attributed to the lower viscosity of the matrix material at higher temperature, thus allowing it flow more easily within the reinforcement, resulting in uniform distribution and better fiber/volume fractions which is responsible for higher tensile strength values. These results agree with some of the researches reported [2426]. The average tensile strength for this combination is $538.8 \mathrm{MPa}$ at $60^{\circ} \mathrm{C}$ processing temperature and then post cured for 24 hours at room temperature, which is comparable $544 \mathrm{MPa}$ reported by Rahmani et al. [27] for similar combination at room temperature bagging and autoclaved at $60^{\circ} \mathrm{C}$ for 12 hours.

\begin{tabular}{|c|c|c|c|c|}
\hline \multicolumn{5}{|c|}{ Table 3: Tensile Strength Results, Mpa } \\
\hline $\begin{array}{c}\text { Tensile } \\
\text { Strength } \\
\text { MPa }\end{array}$ & $20^{\circ} \mathrm{C}$ & $40^{\circ} \mathrm{C}$ & $60^{\circ} \mathrm{C}$ & $80^{\circ} \mathrm{C}$ \\
\hline Sample 1 & 481 & 496 & 528 & 663 \\
\hline Sample 2 & 470 & 499 & 544 & 652 \\
\hline Sample 3 & 490 & 504 & 538 & 659 \\
\hline Sample 4 & 488 & 496 & 541 & 655 \\
\hline Sample 5 & 487 & 493 & 543 & 657 \\
\hline $\begin{array}{c}\text { Average } \\
\text { Value }\end{array}$ & 485 & 497.6 & 538.8 & 657.2 \\
\hline
\end{tabular}

\subsection{Bending strength and Shear Testing}

ASTM D7264M A standard test method for flexural properties of polymer matrix composites is used to measure the bending strength of the samples. A 3point bending test as shown in Fig. 4 is carried out.

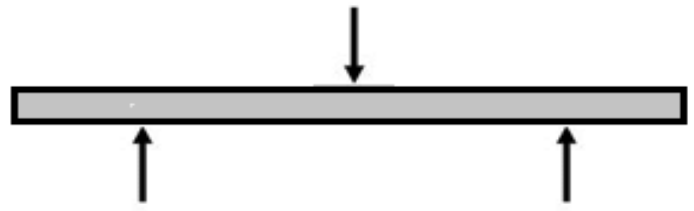

Fig 4: Schematic 3-Point Bending Test

Table 4 presents the results of bending strength test on the same samples. A steady increase in the bending strength can be observed from the table. It should also be noted that the increase is non-linear and variation in bending strength are more significant than variation in tensile strength.

ASTM 5379M Standard test method for shear properties of composite materials by V-notch beam method is used for shear strength properties. sample dimensions of specimen are shown in Fig. 5. 


\begin{tabular}{|c|c|c|c|c|}
\hline \multicolumn{5}{|c|}{ Table 4: Bending Strength Results, Mpa } \\
\hline $\begin{array}{c}\text { Bending } \\
\text { Strength Mpa }\end{array}$ & $20^{\circ} \mathrm{C}$ & $40^{\circ} \mathrm{C}$ & $60^{\circ} \mathrm{C}$ & $80^{\circ} \mathrm{C}$ \\
\hline Sample 1 & 411 & 500 & 660 & 706 \\
\hline Sample 2 & 403 & 481 & 653 & 712 \\
\hline Sample 3 & 406 & 485 & 650 & 710 \\
\hline Sample 4 & 401 & 482 & 650 & 714 \\
\hline Sample 5 & 400 & 489 & 648 & 715 \\
\hline Average value & 404.2 & 487.4 & 652.2 & 711.4 \\
\hline
\end{tabular}

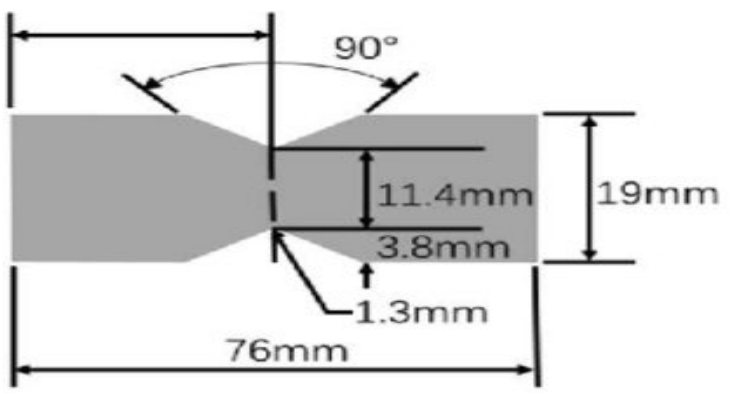

Fig 5: Specimen for Shear Test

Table 5 presents the results of shear strength of laminates. As can be seen from the table, there is a steady increase in shear strength with the increase in temperatures.

The gelling temperature of Araldite 5052 is close to $110^{\circ} \mathrm{C}$, which means that the epoxy will immediately solidify at that temperature and thus not allowing it to flow uniformly across different cross sections in the laminate. Therefore, it was decided that the maximum temperature used will be $80^{\circ} \mathrm{C}$ for processing. A sample was prepared at $95^{\circ} \mathrm{C}$, but it did not allow enough time for the resin to distribute itself smoothly and burning spots were visible on the samples. It should also be noted that provided enough time, the resin is fully cured at even the room temperature.

\begin{tabular}{|c|c|c|c|c|}
\hline \multicolumn{5}{|c|}{ Table 5: Shear Strength Results, Mpa } \\
\hline $\begin{array}{c}\text { Shear } \\
\text { Strength } \\
\text { MPa }\end{array}$ & $20^{\circ} \mathrm{C}$ & $40^{\circ} \mathrm{C}$ & $60^{\circ} \mathrm{C}$ & $80^{\circ} \mathrm{C}$ \\
\hline Sample 1 & 30 & 33 & 39 & 43 \\
\hline Sample 2 & 31 & 35 & 38 & 46 \\
\hline Sample 3 & 29 & 34 & 37 & 47 \\
\hline Sample 4 & 32 & 33 & 38 & 45 \\
\hline Sample 5 & 30 & 36 & 40 & 40 \\
\hline $\begin{array}{c}\text { Average } \\
\text { Value }\end{array}$ & 30.4 & 34.2 & 38.4 & 44.2 \\
\hline
\end{tabular}

\subsection{Comparison of Mechanical Properties}

Fig. 6 shows a comparative plot of variation of mechanical properties presented in Table 1 to Table 3 . It can clearly be seen that the tensile strength is gradually increasing with increasing processing temperature and it was noticed (not presented in the figure) that any further increase in temperature will cause in reduction in the tensile strength.

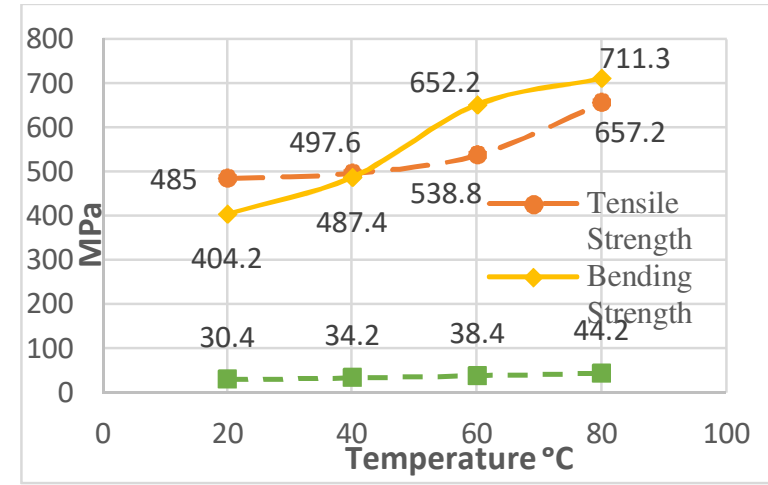

Fig 6: Variation of Mechanical Properties with Varying Temperature

This Fig. also shows the resulting trend in increase in bending and shear strength of composite laminates at higher initial processing temperatures. It should also be noted that these higher initial temperatures not only result in improvement of mechanical properties but also reduce the overall processing time, thus resulting in higher production rates as the curing reaction rates increase at higher temperature (see equation (2)), although, in this research the holding time has not been varied to establish the fundamental relationship between temperature and mechanical properties [28, $29,34,35]$.

It can be noticed from Fig. 6 and Tables 3-5 that fiber volume fraction and studied mechanical properties do not exhibit a linear relationship. This is basically influenced by certain factors like the decreasing resin volume and abnormalities inculcated due to high temperature of processing which affect fiber dominated mechanical properties in a composite [28]. It is also an established fact that the mechanical properties increase with fiber fraction until optimum point only and the same is exhibited in this research. This too is not exactly linear with the fiber increase. Particularly at high fiber fractions the mechanical 
properties tend to behave independently [20]. It can also be seen from Table 4 that the density of the cured composite is increasing with an increase in the processing temperature [30-33].

\subsection{Microscopic Analysis}

The failed samples in all cases were investigated using a scanning electron microscope SEM-Jeol-6490LV. The magnification used was only $10 \mathrm{x}$ as it was understood to be enough to check the failure modes. Tensile test specimens failed diagonally i.e. $45^{\circ}$ as shown in Fig. 7. Continuous strands run through sample that break individually and in small groups and with rise of temperature group of multiple stands broke off as high temperature curing caused better ply bonding. Failure is initiated at voids present in the sample and becomes more pronounced with temperature rise. Bending specimens were in compression on top (center indenter in a three-point system) and under tensile load on the rear supporting surface as shown in Fig. 8. Main failure mechanism is slipping of ply against each other. Temperature rise made outward /breakage of plies under compression which indicates possible brittleness.

Shear specimens were cut at $45^{\circ}$ to the ply layup and lack continuous fibers throughout length as can be seen in Fig. 9. The layers essentially slipped and failed. Test shows mainly matrix strength.

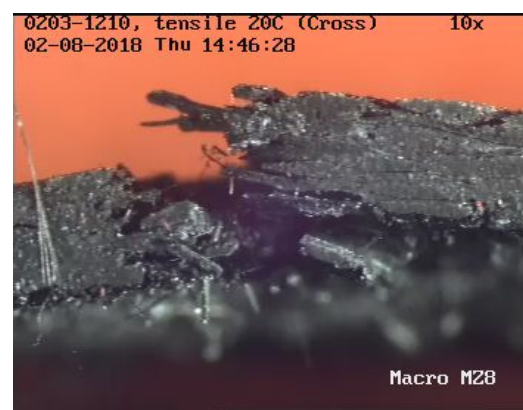

(a)

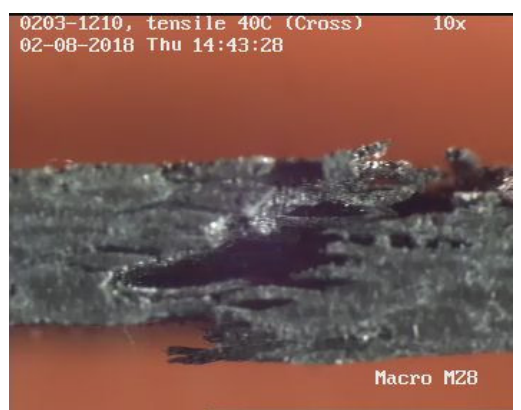

(b)

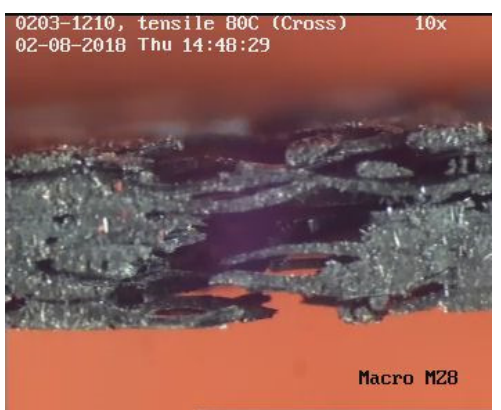

(c)

Fig 7: Enhanced images of failed sample in tensile test
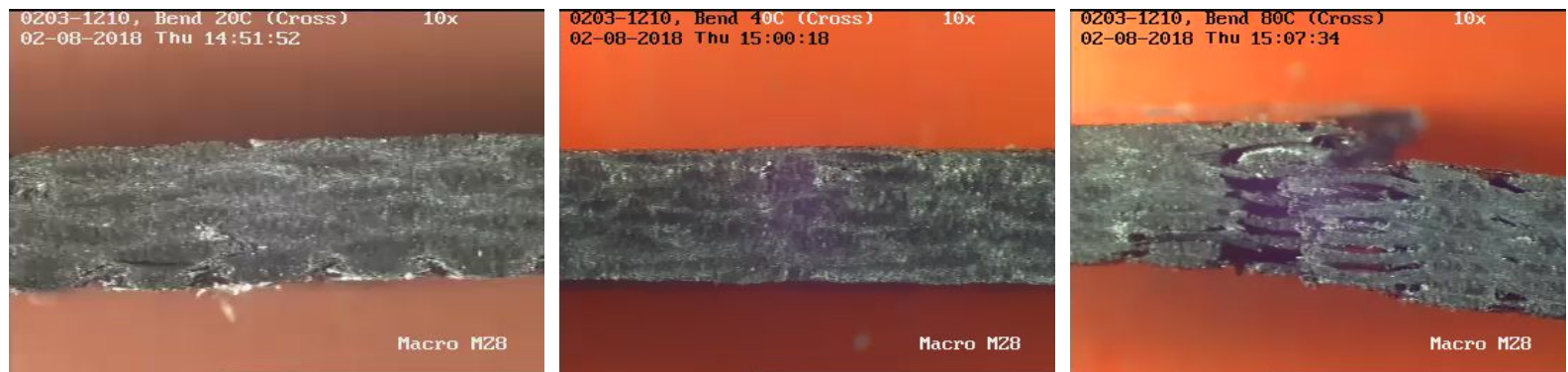

Fig 8: Enhanced images of Sample in bending test

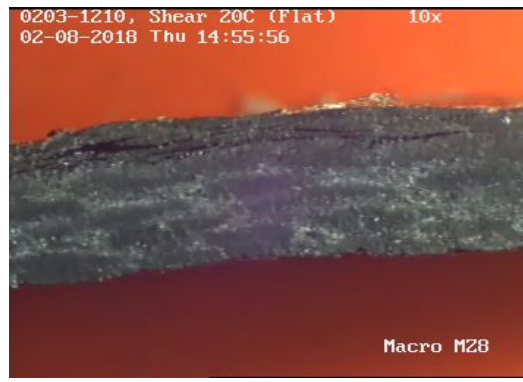

(a)

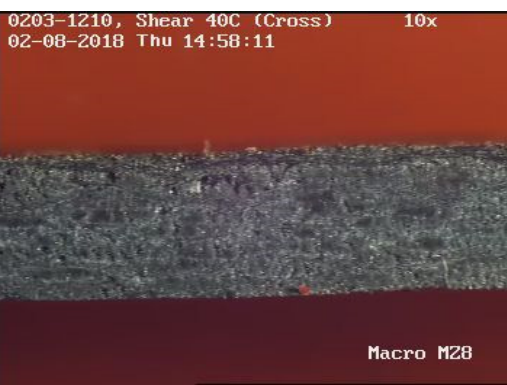

(b)

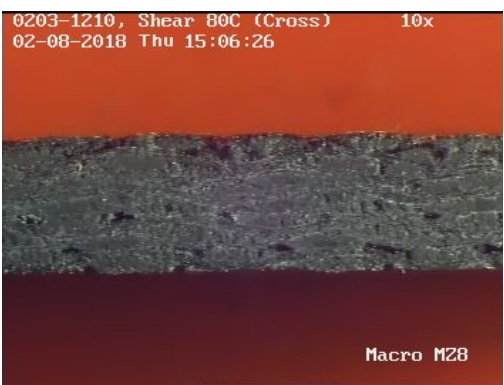

(c)

Fig. 9: Enhanced images of sample in bending test

Mehran University Research Journal of Engineering and Technology, Vol. 40, No. 4, October 2021 [p-ISSN: 0254-7821, e-ISSN: 2413-7219] 


\section{CONCLUSION AND RECOMMENDATIONS}

The tensile strength of the carbon T300 laminates has increased from $481 \mathrm{MPa}$ to $657 \mathrm{MPa}$, while there is significant increase in bending and shear strength at the same time for different processing and curing temperatures as keeping all the other such as fiber orientation, the components and mixing ratios of the matrix materials, the post curing processes, samples machining and testing conditions, constant. Varying initial processing temperature has a significant effect on mechanical properties of carbon composite as follows:

1. The mechanical properties that were tested improved with the increase in initial processing temperature. The optimum processing temperature for plain weaved carbon $3 \mathrm{~K}$ T300 fibers and Araldite Epoxy 5052 is found to be $80^{\circ} \mathrm{C}$ with two hour holding time.

2. It was also noted that better fiber volume and weight fractions are also obtained as a result. It is an indicator of improved resin distribution in laminate, good compaction and economy of resin consumption.

While the study results present some significant improvements in the desired strength parameter, it should be noted that the number of test samples studied in this case is still relatively small. Another study is proposed to include the variation in other important parameters such as pressure and fiber contents. Differential Scanning Calorimetry was not required in this study as all the testing took place after significant time had elapsed from the preparation of samples, however, it is recommended that in-situ curing should be monitored in addition to different holding times for future research for comparison of properties. Moreover, this study shows the results for only one resin plus hardener combination and the results could vary significantly for other combinations. A comprehensive study including different types of matrix materials is recommended for definitive answers to the question of effects of processing parameters on the properties of cured profiles and to produce an analytical model for the effect these parameters.

\section{ACKNOWLEDGEMENT}

The authors acknowledge the support of School of Mechanical and Manufacturing at National University of Science and Technology Islamabad for providing experimental facilities for conducting this research.

\section{REFERENCES}

1. Toor Z.S., "Space applications for composite materials", Journal of Space Technology, Vol. 8, No. 1, pp. 65-70 2018.

2. Hull D., Clyne T.W., "An Introduction to Composite Materials", Cambridge University Press, 2003.

3. Daniel G., "Composite Materials Design and Applications", Taylor and Francis, 2015.

4. Garnier G., Mistou S., Pantalé O., "Influence of process and material parameters on impact response in composite structure: methodology using Design of Experiments", Journal of Structural Analysis of Advanced Materials, Vol. 446, pp. 83-90, 2010.

5. Lu C., Xu N, Zheng T., Zhang X., Xue L., Zhang D., "The optimization of process parameters and characterization of high-performance CF/PEEK composites prepared by flexible CF/PEEK plain weave fabrics", Journal of Polymers, Vol. 11, No. 53, pp. 1-15, 2019.

6. Mohammed R., Zhang F., Sun B., Gu B., "Static and low-viscosity impact on mechanical behavior of foam sandwich composites with different ply angle face sheets". Journal of Composite Materials, Vol. 48, pp. 1173-1188, 2014.

7. Zhang K., Gu Y., Li M., Zhang Z., "Effect of rapid curing process on the properties of carbon fiber/epoxy composite fabricated using vacuum assisted resin infusion molding", Journal of Materials and Design, Vol. 54, pp. 624-631, 2014.

8. Michlowski J., Micociak D., Konstztowicz J., Blazewics S., "Mechanical properties of $\mathrm{C} / \mathrm{C}$ composites processed by wet impregnation and $\mathrm{P}$ - 
CVI Methods". Materials Science, Vol. 46, No. 16, pp. 5587-5594, 2011.

9. Choupin T., "Mechanical performance of PEEK thermoplastic composites linked to their processing parameters", Ecole nationale supérieure d'arts et métiers, pp. 19-58, 2017.

10. Van-Pham D., Nguyen M.T., Nguyen C., Le T.T.D., Pham T.Y.N., Miyata Q., "Effects of processing parameters on mechanical properties and structure of banana fiber-reinforced composites", Journal of Renewable Materials, Vol. 6, No. 6, pp. 662-670, 2018.

11. Tran D.H., Kroisová D., Louda P., Bezucha P., "Effect of curing temperature on flexural properties of silica-based geopolymer-carbon reinforced composite". Journal of Achievements in Materials and Manufacturing Engineering, Vol. 37, pp. 492-497, 2019.

12. Christiyan K.G.J., Chandrasekhar U., Venkateswarlu S., "A study on the influence of process parameters on the mechanical properties of 3D printed ABS composite", Journal of Material Science and Engineering, Vol. 114, pp. 1-8, 2015.

13. Alkan U., Özcanlı Y., Alekberov V., "Effect of temperature and time on mechanical and electrical properties of HDPE/glass fiber composites", Journal of Fibers and Polymers, Vol. 14, No. 1, pp. 115-120, 2013.

14. Schell J., Guilleminot J., Krawczak P., "Computational and experimental analysis of fusion bonding in thermoplastic composites: Influence of process parameters", Journal of Materials Processing Technology, Vol. 209, No. 11, pp. 5211-5219, 2009.

15. Khan L.A., Khan W.A., "Out of Autoclave (OOA) Manufacturing Technologies for Composite Sandwich Structures", Manufacturing Process Modelling and Optimization Strategies, pp. 292-317, IGI Global, 2016.

16. Gadam S.U.K, Roux J.A., Vaughan J.G., "The impact of pultrusion processing parameters on resin pressure rise inside a tapered cylindrical die for glass-fiber/epoxy composites", Journal of Composite Science and Technology, Vol. 60, pp. 945-958, 2000.

17. Kim H.G., "Effects of fiber aspect ratio evaluated by elastic analysis in discontinuous composites",
Journal of Mechanical Science and Technology, Vol. 22, No. 3, pp. 411-419, 2008.

18. Orozco R., "Effects of Toughened Matrix Resins on Composite Materials for Wind Turbine Blades". M.Sc. Thesis, Montana State University, Bozeman, pp. 25-75, 1999.

19. Satish K.G., Siddeswarappa B., Kaleemulla K.M., "Characterization of In-Plane Mechanical Properties of Laminated Hybrid Composites", Journal of Minerals and Materials Characterization and Engineering, Vol. 9, No. 2, pp. 105-114, 2010.

20. Liu L., Zhang B., Wu Z., "Effects of cure cycles on void content and mechanical properties of composite laminates". Journal of Composite Structures, Vol. 73 pp. 303-309, 2006.

21. Balzer B.B., McNabb J., "Significant Effect of Microwave Curing on Tensile Strength of Carbon Fiber Composites". Journal of Industrial Technology, Vol. 24, No. 3, pp. 1-9, 2008.

22. Hang X., Li Y., Xiazhong H., Wen Y., "Effects of temperature profiles of microwave curing process on mechanical properties of carbon-fiber reinforced composites", Journal of Engineering Manufacture, Vol. 231, No. 8, pp. 1-9, 2015.

23. Idris A., Kormin F., Zakiamani M., "The effect of curing temperature on the performance of thin film composite membrane", Journal of Technologi, Vol. 43, No. F, pp. 51-64, 2005.

24. Cadieu L, Kopp J.B., Bumel J., Froustey C., "Temperature effect on mechanical properties and damage mechanism of a glass/thermoplastic laminate", Journal of Composite Materials, Vol. 54, No. 17, pp. 2271-2282, 2020.

25. Im K., Cha C., Kim S., Yang I., "Effects of temperature on impact damages in CFRP composite laminates", Composites Part B, Vol. 32, pp. 669-682, 2001.

26. Akilulu G., Adali S., Bright G., "Temperature effects on mechanical properties of Carbon, Glass and Hybrid polymer composite specimens", International Journal of Engineering Research in Africa, Vol. 39, pp. 119-138, 2018.

27. Rahmani S., Najafi S.M., Ashori A., "Mechanical Properties of epoxy/carbon fiber laminated composites", Reinforced Plastics and Composites, Vol. 33, No. 8, pp. 733-740, 2014. 
28. Dubary N., Taconet G., Bouvet C., Vieille B., "Influence of temperature on impact behavior damage tolerance on hybrid woven -ply thermoplastic laminates for aeronautical applications", Composite Structures, Vol. 168, pp. 663-674, 2017.

29. Xu W.B., Zhou Z.F., Pan W.P., "Cure behavior of epoxy resin/mmt/deta nano composite resin cure meter", Thermal Analysis and Calorimetry, Vol. 78, pp. 1-12, 2004.

30. Rosario K., Liu D., "Quasi-three-dimensional composites for aerospace applications", Journal of Composite Materials, Vol. 44, No. 25, pp. 2953-2973, 2009.

31. Hale D.K, "Physical Properties of Composite Materials". Journal of Materials, Vol. 11, No. 11, 2105-2141, 1976.
32. Campbell F.C., "Structural Composite Materials", ASM International, Ch.4, 2010.

33. Kardos J.L., "Critical issues in achieving desirable mechanical properties for short fiber composites", Pure and Applied Chemistry, Vol. 57, No. 11, pp. 1651-1657, 1985.

34. Khattab A., "Cure Cycle Effect on HighTemperature Polymer Composite Structures Molded by VARTM", Journal of Composites, pp. 1-7, 2013.

35. Mohammed A.H., "The Effect of Curing Time on the Mechanical Properties of Polystyrene Reinforced Alumina Particular Composite", Nahrain University, College of Engineering Journal, Vol. 15, No. 2, pp. 197-205, 2015. 